\title{
Estudo de Impacto de Vizinhança - EIV e sua importância como instrumento de gestão urbana: uma proposta a partir da cidade de Franca/SP 1
}

\section{Neighborhood Impact Study - importance of EIV as an urban management tool: a proposal from Franca city / SP}

\author{
Dal Sasso, Roberlei César1; Meireles, Eduardo².
}

1 Mestrando Profissional do Programa de Desenvolvimento Regional e Meio Ambiente da Universidade do Estado de Minas Gerais - UEMG, Câmpus Passos, Brasil. Rc_dalsasso@hotmail.com.1

2 Professor Doutor Eduardo Meireles, Universidade do Estado de Minas Gerais UEMG, Câmpus Frutal, Brasil. Eduardo.meireles@vemg.br.

\section{RESUMO}

Ao longo do tempo as pessoas passaram a viver em núcleos urbanos. No princípio eram pequenas vilas, chegando aos dias atuais a metrópoles com milhões de habitantes. A vida em cidades facilitou o acesso a diversas oportunidades: emprego, educação, saúde, cultura e lazer. Porém, essa disponibilidade de serviços e atrações também causam efeitos negativos, caso não haja planejamento. O aumento da importância da gestão do espaço urbano e da conscientização acerca das questões ambientais trouxe a necessidade de realização de estudos que analisem as consequências da instalação de empreendimentos em espaços urbanos. O Estudo de Impacto de Vizinhança - EIV pode contribuir para a construção de um espaço urbano mais equilibrado. Para isso, o trabalho avaliará a efetividade dos estudos realizados no município de Franca/SP, usando o EIV do SESC na cidade como parâmetro e propondo um Termo de Referência para padronizar elaboração e análise dos estudos. A proposta é uma adaptação de Lollo e Rohm (2005) que se baseia na divisão em cinco eixos: Meio Físico, Aspectos Urbanísticos, Infraestrutura Urbana, Saneamento e Qualidade de Vida e Impactos Socioeconômicos; e na posterior análise dos impactos levantados e de suas medidas mitigadoras e/ou potencializadoras.

Palavras-chave: Estudo de Impacto de Vizinhança, Estatuto da Cidade, Gestão e Planejamento Urbano.

\section{ABSTRACT}

Over time, people began to live in urban centers. In the beginning they were small towns, reaching today the metropolis with millions of inhabitants. Life in cities has facilitated access to various opportunities: employment, education, health, culture and leisure. However, this

\footnotetext{
${ }^{1}$ DAL SASSO, Roberlei; MEIRELES, Eduardo. Estudo de Impacto de Vizinhança - EIV e sua importância como instrumento de gestão urbana: uma proposta a partir da cidade de Franca/SP. In: II SIMPÓSIO NACIONAL DE GESTÃo E ENGENHARIA URBANA: SINGEURB, 2019, São Paulo. Anais... Porto Alegre: ANTAC, 2019.
} 
availability of services and attractions also have negative effects if there is no planning. Increasing the importance of urban space management and raising awareness about environmental issues has led to the need to carry out studies that analyze the consequences of setting up projects in urban spaces. The Neighborhood Impact Study - ElV can contribute to the construction of a more balanced urban space. For this, the work will evaluate the effectiveness of the studies carried out in Franca City/ SP, using the SIV of the SESC in the city as a parameter and proposing a Term to standardize the preparation and analysis of the studies. The proposal is an adaptation of Lollo and Rohm (2005) that is based on the division into five axes: Physical Environment, Urban Aspects, Urban Infrastructure, Sanitation and Quality of Life and Socioeconomic Impacts; and the subsequent analysis of the impacts raised and their mitigating and / or enhancing measures.

Keywords: Neighborhood Impact Study, City Statute, Urban Planning and Management.

\section{INTRODUÇÃO}

A cidade de Franca está localizada na região nordeste do Estado de São Paulo e, de acordo com dados do CENSO IBGE (2010), possuía 318.640 pessoas, sendo 98,23\% moradores da área urbana. O dado mais recente do IBGE (População estimada 2017) indica o total de 347.237 habitantes (aumento de quase $9 \%$ nesse período).

A ocupação do espaço urbano, de acordo com Serra (2014, p. 769) é um processo de adaptações espaciais oriundo da busca das satisfações humanas socialmente definidas. Essas modificações e adaptações e os interesses difusos de diferentes grupos, leva a conflitos sociais e urbanos. Cymbalista (2001) esclarece que mesmo que o imóvel esteja dentro do que determina a Lei, sua utilização não diz respeito somente ao proprietário da área e ao poder público. Para mediar os conflitos a realização de estudos que avaliem os impactos causados no espaço urbano se faz necessário. No caso brasileiro, após anos de debate e de algumas experiências isoladas, como nos casos das cidades de São Paulo e Porto Alegre, foi definido o EIV como o instrumento de análise dos impactos da instalação de novas atividades nas cidades. Essa definição veio no primeiro momento nos artigos 182 e 183 da Constituição de 1988, em um capítulo específico sobre a Gestão Urbana. A regulamentação somente foi realizada com a promulgação da Lei Federal n 10.257, de 10/07/2001, conhecida como Estatuto da Cidade. Em seu artigo 37 é indicado em quais situações o EIV deverá ser elaborado. Porém, para a execução dos instrumentos previstos no Estatuto da Cidade, é necessário regulamentação por parte do município através de uma Lei Complementar.

O processo de regulamentação do EIV ocorreu na cidade de duas maneiras: primeiro para empreendimentos particulares e posteriormente empreendimentos públicos. No ano de 2011 - Código de Meio Ambiente Municipal foi alterado para incorporar a necessidade de elaboração do ElV para os empreendimentos listados no Artigo 10. No ano de 2016, através da Lei Complementar $n^{\circ} 266$ determinou que condomínios horizontais de Prédio de até 3 pavimentos ou até 3 unidades habitacionais estariam dispensados da realização do EIV para regularização junto a Prefeitura. Em relação a empreendimentos realizados pelo poder público, a regulamentação veio em 2012, através da Lei Complementar n 206.

Mesmo existindo Legislação federal sobre o tema, há algumas deficiências que podem ser observadas nos Estudos realizados no País. (Lollo \& Rohm, 2005). Ainda segundo os autores, essas deficiências podem ser divididas em duas situações: falhas de legislação e de forma de condução dos trabalhos, sendo o caso de Franca. Não há detalhes nas normatizações municipais em como deve ser elaborado os estudos, apenas os mesmos itens listados no Estatuto da Cidade, e a cada empreendimento há uma metodologia de avaliação proposta. 


\section{REVISÃO BIBLIOGRÁFICA}

\subsection{Gestão Urbana - O ontem e hoje}

Os benefícios trazidos pela vida em cidades são notórios. A maior facilidade de acesso aos serviços nas mais diversas áreas, tais como saúde, educação, lazer, emprego, moradia entre outras, é fácil perceber. Assim como é claro que o acesso às vantagens trazidas pela vida em centros urbanos não está dividida de forma equilibrada. A concentração da população em centros urbanos aumentou rapidamente e de acordo com Maricato (2004), a quantidade de brasileiros que vivem em cidades atingiu mais de $80 \%$ no ano 2000 . E esse valor ainda aumentou, de acordo com Lopes, para $85 \%$, com estimativas que chegue aos $90 \%$ no ano de 2020. Esse aumento de pessoas vivendo em cidades ocorreu pelo êxodo rural, onde contingentes de pessoas saíram de zonas rurais e foram para as cidades em busca de oportunidades de emprego, que segundo Marques (2010) ocorreu devido à alteração do processo produtivo na área rural e a consequente diminuição da necessidade de mão-deobra. Essas pessoas foram forçadas a buscar vagas nas áreas urbanas, principalmente na atividade industrial.

De acordo com Rocco (2006), o homem busca a adaptação ao meio ambiente natural através da construção de outro ambiente. Esse outro ambiente é construído para que se tenha habitabilidade, conforto e segurança para sua sobrevivência. É importante a distinção entre ambientes naturais e o ambiente construído (ou ambiente urbano) para entender as relações do homem e seus consequentes impactos.

A Constituição de 1988 incluiu dois artigos a respeito da Reforma Urbana (Artigos 182 e 183). Apesar de ser uma grande vitória, os referidos artigos somente foram regulamentados em 2001. De acordo com Rolnik et.al. (2005) a Lei com os instrumentos para a implantação da Política Urbana, inicialmente proposta pelo senador Pompeu de Souza, após muita negociação entre setores da sociedade foi regulamentada como a Lei Federal $n^{\circ} 10.257$, conhecida como Estatuto da Cidade.

\subsection{Estudo de Impacto de Vizinhança e o surgimento de uma perspectiva de regulação da produção no espaço urbano.}

A partir da regularização do Estatuto da Cidade, em 2001, vários instrumentos de gestão urbana foram legalizados. Ainda segundo Rolnik et al (2005), o principal desses instrumentos é - Plano Diretor e sua construção deve ser realizada a partir da participação popular de todos os setores da sociedade. Entre outros instrumentos no âmbito municipal regulamentados pelo Estatuto da Cidade estão: disciplina do parcelamento, do uso e da ocupação do solo, zoneamento ambiental, gestão orçamentária participativa, IPTU, direito de preempção, Estudo de Impacto de Vizinhança - EIV. Porém, mesmo antes da regulamentação do EIV como um instrumento de gestão urbana, algumas cidades criaram mecanismos de avaliação dos impactos em ambientes urbanos. Os principais exemplos são as cidades de Porto Alegre, no Rio Grande do Sul e São Paulo.

\subsection{EIV - Regulamentação através do Estatuto da Cidade}

O EIV está descrito na Seção XII do Estatuto da Cidade, com os artigos 36 a 38. Rocco (2006) define que o EIV é um novo instrumento com o objetivo de mediar interesses entre empreendimentos urbanos, gestores públicos e o cidadão comum. Essa mediação se faz necessário para que a utilização de um imóvel/empreendimento não venha a prejudicar a vizinhança e o seu fluxo urbano, conforme descritos entre os artigos 1.277 e 1.281 do Código Civil Brasileiro. A adoção do EIV como um instrumento de gestão urbana propõe reforçar a ideia de que a utilização do imóvel urbano não diz respeito somente ao proprietário. Os referidos artigos determinam os parâmetros de perturbação a vizinhança em relação à segurança, sossego e a saúde. 0 artigo 36 do Estatuto da Cidade define que lei municipal específica determinará quais empreendimentos e atividades deverão fazer o Estudo. O artigo 37 determina que a avaliação deva ser realizada levando em consideração os efeitos 
positivos e negativos do empreendimento em questão, tendo, no mínimo, as seguintes questões:

I- Adensamento populacional; II - Equipamentos urbanos e comunitários; III - Uso e ocupação do solo; IV - Valorização imobiliária; $\vee$ - Geração de tráfego e demanda por transporte público; VI - Ventilação e iluminação; VII - Paisagem urbana e patrimônio natural e cultural. O artigo 38 deixa claro que a realização do EIV não substitui a elaboração do Estudo de Impacto Ambiental - EIA. (EC, 2001).

A necessidade de realização do EIV para situações apresentadas acima, de acordo com Marques (2010), cria um instrumento democrático que incentiva a participação da população, e ao contrário do que possa parecer melhora a qualidade e aceitação do empreendimento junto à comunidade próxima e da sociedade como um todo.

\section{METODOLOGIA}

A metodologia de trabalho empregada neste projeto será dividida em duas etapas: a primeira é uma revisão bibliográfica acerca das questões técnicas e legais do tema e de práticas já adotadas em cidades do Brasil. No segundo momento, a partir da adaptação de metodologia proposta por Lollo e Rohm (2005), propor uma ferramenta para padronizar a realização e análise dos EIV realizados no município de Franca, tendo como padrão o Estudo realizado para a construção do Serviço Social do Comércio - SESC, na cidade de Franca/SP.

\section{RESULTADOS}

Os EIV elaborados na cidade de Franca são analisados pelo Grupo Técnico de Análises - GTA. Para o acesso aos estudos é necessária a requisição junto a Secretaria de Planejamento da Prefeitura Municipal. A partir desse momento foi possível ter acesso ao EIV relacionado à construção da unidade do SESC na cidade.

Para a análise do EIV foi realizada adaptação de metodologia proposta por Lollo \& Rohm (2005). Primeiro os aspectos relacionados ao empreendimento são divididos em cinco eixos, sendo eles: Meio Físico (ar, solo, rocha, mananciais superficiais, mananciais subterrâneos, paisagem natural, vegetação e uso e ocupação do solo); Aspectos Urbanísticos (densidade populacional, densidade urbana, mercado imobiliário, ventilação, iluminação, paisagem urbana, patrimônio cultural, qualidade urbanística); Infraestrutura Urbana (vias urbanas, transporte coletivo urbano, redes de água, esgoto, drenagem pluvial, energia elétrica, telefonia, iluminação e segurança pública); Saneamento e Qualidade de Vida (ruído, resíduos sólidos urbanos, resíduos líquidos urbanos, resíduos industriais e impactos físicos sobre construções vizinhas) e Aspectos socioeconômicos (emprego, arrecadação e geração de serviços).

O EIV referente ao SESC identificou 24 impactos, sendo 16 na fase de construção e oito na operação. A Tabela 1 detalha a classificação dos impactos de acordo com a proposta de um Termo de Referência:

Tabela 1 - Listagem de impactos do EIV - SESC Franca/SP

\begin{tabular}{llllll}
\hline Elementos & Meio & $\begin{array}{l}\text { Aspectos } \\
\text { Frbásico }\end{array}$ & $\begin{array}{l}\text { Infraestrutura } \\
\text { Urbana }\end{array}$ & $\begin{array}{l}\text { Saneamento } \\
\text { e Qualidade } \\
\text { de Vida }\end{array}$ & $\begin{array}{l}\text { Aspectos } \\
\text { Socioeconômicos }\end{array}$ \\
$\begin{array}{l}N^{\circ} \text { de Impactos } \\
\begin{array}{l}\text { Construção } \\
N^{0} \text { de Impactos } \\
\text { Operação }\end{array}\end{array}$ & 01 & 01 & 01 & 02 & 04 \\
\hline
\end{tabular}




\section{CONCLUSÕES}

O êxito na utilização do EIV como um instrumento de planejamento urbano possui diversos exemplos no País. Várias cidades incorporaram o estudo de maneira a contribuir nas tomadas de decisão. A cidade de Franca possui legislação específica sobre o tema e corpo técnico para analisar os estudos, porém o documento ainda está relacionado a um processo simplesmente burocrático e protocolar, não funcionando como um instrumento de planejamento ou até mesmo de gestão urbana. A construção de um Termo de Referência com o intuito de facilitar o processo de elaboração e análise poderia contribuir para seu uso mais amplo.

\section{REFERÊNCIAS}

BRASIL. Constituição (1988). Constituição da República Federativa do Brasil, DF. Senado: Coordenação de Edições Técnicas, 2016. 496 p.

BRASIL. Lei Federal $n^{\circ} 10.257$ de 10 de Julho de 2001.

BRASIL. Lei Federal n 10.406, de 10 de Janeiro de 2002.

CYMBALISTA, Renato. Estudo de Impacto de Vizinhança. Disponível em:

<http://polis.org.br/publicacoes/estudo-de-impacto-de-vizinhanca/>. Acesso em Instituto Polís. Acesso em 18 de Setembro de 2017.

FRANCA. Lei Complementar $n^{\circ}$ 206, de 26 de Junho de 2012.

FRANCA. Lei Complementar n 266, de 26 de Abril de 2016.

IBGE INSTITUTO BRASILEIRO DE GEOGRAFIA E ESTATístICA. (2010). Censo Demográfico. Rio de Janeiro: IBGE. Recuperado em 18 de Setembro de 2017, de www.ibge.gov.br.

IBGE INSTITUTO BRASILEIRO DE GEOGRAFIA E ESTATÍSTICA. (2017). População estimada. Rio de Janeiro: IBGE. Recuperado em 18 de setembro de 2017, de www.ibge.gov.br.

LOLLO, J.A.; ROHM, S.A. Proposta de Matriz para Levantamento e Avaliação de Impactos de Vizinhança. Holos Environment, v. 5, n. 2, p. 169-183, 2006.

MARICATO, Erminia. Caderno MCidades, Ministério das Cidades, Desenvolvimento Urbano, Distrito Federal. (2004)

MARQUES, Janaína da Silva. Estudo de Impacto de Vizinhança: Uma Análise Crítica feita por Meio dos Relatórios de Impacto de Vizinhança apresentados no DF. Brasília:UnB, 2010. 164 f. Dissertação (Mestrado em Arquitetura e Urbanismo) - Programa de Pós Graduação em Arquitetura e Urbanismo, Faculdade de Arquitetura e Urbanismo, Universidade de Brasília, Brasília, 2010.

ROLNIK, Raquel; SCHABERG, Benny; PINHEIRO, Otilie Macedo (Coord.). (2005). Plano Diretor Participativo. Brasília: Ministério das Cidades, Secretaria Nacional de Programas Urbanos.

ROCCO, Rogério. Estudo de Impacto de Vizinhança: Instrumento de Garantia as Cidades Sustentáveis. Rio de Janeiro: Lumen Juris, 2006.

SERRA, Geraldo Gomes. Questão Urbana e Participação no Processo de Decisão. In: Philippi Jr. Arlindo; Romêro, Marcelo de Andrade; Bruna, Gilda Collet. (Orgs) Curso de Gestão Ambiental. São Paulo: Manole, 2014. 